\title{
Aspectos fármaco-epidemiológicos de la enfermedad respiratoria bovina bacteriana en feedlots. Una problemática a resolver
}

\author{
de Yaniz, M.G.,; Sánchez Bruni, S.F.,3,4 \\ ${ }^{1}$ Área de Patología, ${ }^{2}$ Área Farmacología, ${ }^{3}$ Investigador CONICET, ${ }^{4}$ Centro Investig. Vet. Tandil (CIVETAN- \\ CONICET). Facultad Cs. Veterinarias, Univ. Nac. Centro Prov. Bs.As., B7000-Tandil, Buenos Aires, \\ Argentina. TE+54-0249-4439850. E-mail: gdeyaniz@vet.unicen.edu.ar
}

\begin{abstract}
Resumen
de Yaniz, M.G.; Sánchez Bruni, S.F.: Aspectos fármaco-epidemiológicos de la enfermedad respiratoria bovina bacteriana en feedlots. Una problemática a resolver. Rev. vet. 26: 2, 160-167, 2015. La enfermedad respiratoria bovina (ERB) es un proceso infeccioso multifactorial, causado principalmente por virus, bacterias y parásitos. Generalmente afecta a los bovinos menores de dos años de edad en crianza a feedlot, siendo una de las principales causas de morbi-mortalidad en esta categoría. Su tratamiento farmacológico llega a representar un $8 \%$ del total de los costos de producción, con alto porcentaje de fracasos terapéuticos. Las tasas de mortalidad debida a ERB son de aproximadamente 50\%, presentándose la mayor parte en los primeros 45 días de ingresados los animales al feedlot. Tales fallas terapéuticas se deben a la ausencia de un diagnóstico basado en la evidencia y a la falta de protocolos de terapéutica racional, lo cual impide la correcta identificación de las cepas actuantes, conduciendo al tratamiento empírico de los animales y al desarrollo de resistencia bacteriana. Debido a que Argentina adolece de una falta de información sobre cepas resistentes en animales bajo condiciones de cría en feedlot, consideramos necesario difundir estrategias para optimizar una terapia antimicrobiana basada en evidencia científica, con rotación química de principios activos en animales naturalmente afectados. Se estima que ello incidirá en la reversión del uso indiscriminado de antibióticos y en la aparición de cepas bacterianas resistentes.
\end{abstract}

Palabras clave: bovino, feedlot, neumonía, antimicrobianos, resistencia.

\begin{abstract}
de Yaniz, M.G.; Sánchez Bruni, S.F.: Pharmaco-epidemiological aspects of bacterial bovine respiratory disease in feedlots: A problem to solve. Rev. vet. 26: 2, 160-167, 2015. Bovine respiratory disease (BRD) is a multifactorial infectious disease mostly caused by viruses, bacterias and parasites. It usually affects cattle less than 2 years-old in feedlots and is one of the leading causes of morbility and mortality in this category. The pharmacological treatment of BRD involves the $8 \%$ of the total production costs, with high failure rates. Approximately $50 \%$ of total mortality takes place during the first 45 days within a feeding period. The lack of evidence-based diagnosis and no identification of bacterial strains together with the empirical pharmacological treatment, probably contributes to the development of bacterial resistance. Due to the lack of information on resistant strains in feedlot animals in Argentina, it was considered necessary to optimize antimicrobial therapy based on scientific evidence with chemical rotation of active pharmaceutical ingredients in naturally affected animals. It is expected that this will promote the reversion of the indiscriminate use of antibiotics and the appearance of resistant bacterial strains.
\end{abstract}

Key words: cattle, feedlot, pneumonia, antimicrobials, resistance.

\section{INTRODUCCIÓN}

En Argentina existen aproximadamente 50 millones de cabezas de ganado vacuno, de los cuales más de 20 millones son vacas. Anualmente nacen alrededor de

Recibido: 8 junio 2015 / Aceptado: 14 setiembre 2015
13 millones de terneros, siendo la eficiencia reproductiva nacional apenas cercana al $63 \%$. Sin embargo debido a la intensificación de los sistemas en los encierres a corral (feedlots), el país ha podido mantener una producción de carne que oscila alrededor de 3 millones de toneladas equivalente res con hueso por año. Durante el 
2014 se faenaron 12.100 .979 cabezas de ganado bovino, $33,52 \%$ terneros y $20,86 \%$ novillitos ${ }^{42}$.

Como sucedió en otros países, tal intensificación generó nuevos desafíos sanitarios ya que el aumento de la carga animal instantánea (animales por unidad de superficie), favoreció la presentación de enfermedades de alta morbilidad y mortalidad, repercutiendo negativamente sobre la rentabilidad del negocio. Se ha reportado que en el país la tasa de letalidad del ganado en engorde oscila entre 1 y $2 \%$, siendo las enfermedades respiratorias las responsables de más de la mitad de estas muertes ${ }^{10,36,45}$, tasas que resultan coincidentes con las registradas en otros países ${ }^{31,48,49,54}$.

El avance de estos sistemas intensivos incidió en el aumento de las enfermedades infecciosas y por ende en la mayor utilización de drogas antimicrobianas. Tales tratamientos son implementados en forma metafiláctica o en forma específica en animales enfermos, lo cual ha llevado inexorablemente a la aparición de bacterias resistentes a los antimicrobianos disponibles en el mercado. El aumento de la resistencia bacteriana a los antibióticos (ATB) representa una importante amenaza sanitaria, lo cual sumado a la ausencia casi total de fármacos antimicrobianos en desarrollo, se ha convertido en un serio problema de salud pública.

En Argentina existen escasos reportes de investigaciones que hayan evaluado resistencia a los antimicrobianos. En uno de ellos se determinó que el 55\%, 90,5\% y $77,8 \%$ respectivamente de las cepas de Histophilus somni, Mannheimia haemolytica y Pasteurella multocida aisladas de pulmones bovinos, fueron resistentes al menos a uno de los ATB estudiados, presentando mayores niveles de resistencia a eritromicina, gentamicina y kanamicina ${ }^{15}$. Otros autores -en cambio- determinaron mayor resistencia a las tetraciclinas ${ }^{34}$.

El presente trabajo tuvo como objetivo revisar aspectos generales de la enfermedad respiratoria bovina (ERB) bacteriana y sus particularidades fármacoepidemiológicos en sistemas intensivos de feedlots. Se enfatizó la problemática situación actual y los conocimientos acerca de la presencia de resistencia bacteriana a determinados agentes biocidas y su importancia en la salud tanto animal como humana.

\section{DESARROLLO}

\section{Agentes etiológicos involucrados en la ERB}

La ERB es una enfermedad infecciosa multifactorial, causada principalmente por virus (herpes virus bovino-1, virus de la diarrea viral bovina, parainfluenza-3, virus sincitial respiratorio bovino), bacterias (Mannheimia haemolytica, Pasteurella multocida, Histophilus somni), parásitos (Dictyocaulus viviparus) y Mycoplasma bovis ${ }^{19,41,51}$.

En EEUU se analizaron registros de feedlots y se agruparon las causas de morbilidad del ganado bovino alojado en un mismo corral. Los resultados indicaron que del total de morbilidad, 67 a $82 \%$ de los casos fueron debidos a enfermedades respiratorias, 3 a $7 \%$ a desórdenes digestivos y 14 a 28\% a desórdenes misceláneos como prolapsos, cálculos urinarios e injurias, resaltando la importancia que las enfermedades respiratorias asumen en estos sistemas ${ }^{14}$.

En feedlots se ha reportado que la tasa de mortalidad por ERB oscila en el 50\% de los animales afectados y que la mayor parte de las muertes ocurre en los primeros 45 días de ingresados los animales a los corrales ${ }^{10,14,49}$. En países del hemisferio norte, las pérdidas económicas recientemente estimadas fueron de tres billones de dólares anuales, a causa de la mortalidad, los gastos en tratamientos y profilaxis, además de la disminución de la performance de los animales, aumento de los días de alimentación, bajo peso de la carcasa, calidad disminuida y aumento de la labor humana ${ }^{19,39,48}$.

Se calcula que aproximadamente el $25 \%$ de los terneros experimentan al menos un episodio de enfermedad respiratoria durante el primer año de vida, con tasas que van de 14 a $38 \%$; estas incidencias resultan mayores en terneros que en terneras, tanto en las etapas previas al destete como en los períodos de engorde. El costo de tratamiento llega a representar un $8 \%$ del total de los costos de producción, evidenciando un alto impacto económico negativo ${ }^{26,56}$.

Aunque el mayor impacto es la mortalidad, las pérdidas subclínicas generadas por la ERB son dignas de tener en cuenta, dada la diferencia entre las ganancias de peso diario de animales enfermos versus sanos. Durante un ensayo de 90 días realizado en Canadá, los terneros que experimentaron un episodio de ERB registraron $0,18 \mathrm{~kg}$ menos de ganancia de peso diario que aquellos sanos, y los que ostentaron dos o más brotes tuvieron $0,33 \mathrm{~kg}$ menos, mostrando una performance negativa y ausencia de ganancia de peso compensadora ${ }^{38}$.

En los feedlots la ERB se caracteriza por una severa bronconeumonía y/o pleuroneumonía y es considerada como una enfermedad multifactorial en la cual por lo menos hay un organismo bacteriano implicado. Los factores de riesgo involucrados en la enfermedad incluyen infecciones previas o en paralelo con agentes virales, mala nutrición y/o medidas de manejo inadecuadas, los cuales pueden producir supresión de la respuesta inmune del hospedador. Entre las medidas de manejo no adecuadas se incluyen la superpoblación, destetes anticipados, condiciones de transporte desfavorables y trastornos medioambientales ${ }^{9,26}$.

Los agentes bacterianos involucrados en la ERB son en su gran mayoría capaces de colonizar el tracto respiratorio superior de animales sanos ${ }^{1,9,18}$, siendo los microorganismos de la familia Pasteurellaceae los más frecuentemente involucrados. Así, estudios recientes han reportado prevalencias nasales de H. somni, M. bovis, M. haemolytica y P. multocida de $42 \%, 4,8 \%, 13,4$ y $26 \%$ respectivamente, en animales de feedlot clínicamente sanos ${ }^{37}$. Estos estudios son coincidentes con otros reportes, aunque los porcentajes de aislamientos de los agentes bacterianos variaron en su proporción ${ }^{18}$. 
Manhemia haemolytica (familia Pasteurellaceae) es una bacteria cocobacilar gram-negativa considerada como el patógeno bacteriano mas importante en la ERB ${ }^{20,44,56}$. Reportes en ganado de engorde han determinado prevalencias de $M$. haemolytica en lavajes nasales que oscilan entre 2 y $33 \%$ en animales clínicamente sanos ${ }^{18,37}$. Dicha bacteria presenta habilidad de fermentar arabinosa, habiéndose descripto 12 serotipos (A1, A2, A5, A6, A7, A8, A9, A12, A13, A14, A16 y A17) de los cuales A1, es conocido por ser el mayor causante de ERB ${ }^{44,50}$.

Bovinos sanos son frecuentemente portadores de M. haemolytica serotipo A2 en el tracto respiratorio superior, pero luego de un proceso de estrés o una coinfección, A1 toma rápidamente el lugar de A2, probablemente por transferencia horizontal de otros animales enfermos ${ }^{56}$. Luego de la proliferación del serotipo A1 en el tracto respiratorio alto, colonizan el tracto respiratorio inferior y finalmente se alojan en la entrada de los espacios alveolares ${ }^{44}$.

$M$. haemolytica A1 fue la especie más frecuentemente aislada en 80 terneros examinados en necropsias realizadas en 40 brotes de ERB ${ }^{1}$. En muestras de nasofaringe, otros investigadores lograron identificar los serotipos A2, A1 y A6, no habiendo detectado los serotipos A7 y A9 ${ }^{29}$. Si bien en el $74,4 \%$ de las muestras analizadas se aisló el serotipo A2, estos resultados fueron esperables ya que los animales en estudio no presentaban signos clínicos de ERB y dicho serotipo es considerado no patogénico en el ganado, siendo comensal de la flora normal respiratoria. Si bien los aislamientos del serotipo A1 fueron del 11\%, tal cifra se incrementó al $38 \%$ en cepas aisladas en los animales luego de haber manifestado signos clínicos de enfermedad respiratoria y haber sido tratados con antimicrobianos ${ }^{29}$. Ello podría relacionarse a la actual resistencia de este serotipo a los fármacos utilizados para el tratamiento de ERB. En anteriores aislamientos, el $80 \%$ de los casos de $M$. haemolityca de tejido pulmonar correspondieron al serotipo A1, el 3,6\% al serotipo A2 y el $16,3 \%$ al serotipo A6 ${ }^{30}$, siendo estos resultados coincidentes con reportes previos ${ }^{28,44}$.

Diversos estudios se han realizado analizando la diversidad genética de los aislamientos de $M$. haemolytica, explicando que la presión de selección que ocurriría en el periodo de engorde, podría posiblemente resultar en una sustancial alteración en el genoma de dicha bacteria, si dicho nivel de plasticidad in vivo ocurriera al igual que lo reportado in vitro ${ }^{29,53}$. Estos estudios son coincidentes con los resultados de autores que reportaron que los serotipos de M. haemolytica involucrados en la ERB fueron mayormente A1 y A6, habiéndose mencionado que A6 constituyó el 30\% del total de serotipos aislados ${ }^{44}$.

$M$. haemolytica posee varios factores de virulencia asociados a la patogénesis, entre los que han sido reportados adhesinas, polisacárido capsular, lipopolisacárido (LPS), neuraminidasas, proteína de unión al hierro, enzimas secretorias, leucotoxina y toxina RTX específica de rumiantes (LKT). LPS y LKT son los dos factores de virulencia más importantes, siendo responsables de las lesiones ocasionadas en la infección por M. haemolytica. LPS tiene propiedades endotóxicas y proinflamatorias, causando vasculitis y complejándose con LKT para aumentar la producción de receptores para LKT. El factor LKT induce cambios en los leucocitos bovinos como el aumento del riesgo de lisis osmótica, formación de poros de membrana y necrosis o liberación de citoquinas proinflamatorias y radicales libres, entre otras. Adhesinas específicas como glicoproteínas, N-acetil-D-glucosamina, OmpA y lipoproteína 1 , median la adherencia a las células del epitelio traqueal y activan el daño oxidativo de los neutrófilos, colaborando en la colonización. La cápsula de $M$. haemolytica puede funcionar como adhesina además de tener propiedades antifagocíticas, interviniendo de este modo en la adhesión e invasión de la bacteria. Las neuraminidasas reducen la viscosidad del mucus permitiendo de este modo el acceso de las bacterias a la superficie epitelial ${ }^{21,26,32,50}$.

Pasteurella multocida (familia Pasteurellaceae) es una bacteria cocobacilar gram-negativa que -hasta el momento- posee 5 serogrupos capsulares (A-F) y 16 serotipos somáticos (1-16) ${ }^{21}$. Como factores de virulencia también posee adhesinas, polisacárido capsular y LPS, los cuales participan de la patogénesis de la enfermedad ${ }^{11}$.

Las adhesinas son las responsables de la adherencia de las bacterias y colonización de la superficie celular; dentro de éstas se incluyen: fimbria tipo IV, OmpA, neuraminidasa y hemaglutinina filamentosa (FHA). Además, OmpA y varias proteínas de unión al hierro, así como la proteína A de unión a la hemoglobina y la proteína A de unión a la transferrina, junto a otras proteínas de la matriz extracelular, colaboran en la invasión de la bacteria. La importancia de la cápsula como factor de virulencia determinante en la patogénesis de P. multocida es debida a las propiedades antifagocíticas que ésta presenta. El LPS es un potente estimulador de citoquinas inflamatorias y predominante incitador de la inflamación a nivel pulmonar ${ }^{6,32,41}$.

Dicha bacteria es considerada, al igual que M. haemolytica, un organismo comensal en animales sanos, aislándose de secreciones nasales de terneros con enfermedad respiratoria clínica dos o más veces que lo aislado en terneros clínicamente sanos ${ }^{21}$.

Las especies del género Histophilus (familia Pasteurellaceae) son bacterias pleomórficas, bacilos o cocobacilos gram-negativos, anaerobios facultativos, caracterizados por fermentar carbohidratos y reducir nitratos. Son parásitos obligados de la superficie mucosa de sus hospedadores mamíferos y no resisten largos períodos de tiempo en el medio ambiente. Histophilus somni es una bacteria encapsulada y dentro de sus factores de virulencia se citan: alteraciones de los componentes de los lipooligosacáridos (LOS), sialilación de los LOS, unión e inducción de apoptosis de células endoteliales bovinas, proteínas de unión a la región $\mathrm{Fc}$ 
de las inmunoglobulinas, sobrevida intracelular, inhibición de radicales oxígeno, producción de exopolisacáridos y formación de biofilm ${ }^{24,32,47}$.

Agentes infecciosos como Micobacterium bovis, Trueperella pyogenes y Bibersteinia trehalosi son citados como productores de ERB, aunque su incidencia es menor que las mencionadas anteriormente.

\section{Presentación y signos clínicos}

La neumonía asociada a la presencia de bacterias como M. haemolytica, P. multocida o $H$. somni ocurre a menudo cuando la defensa inmunológica de los animales se encuentra comprometida. Tal compromiso puede ocurrir por daño del epitelio del tracto respiratorio ocasionado por el virus de la rinotraqueítis infecciosa bovina (IBR), el paramixovirus de la parainfluenza bovina (PI-3) o el virus sincitial respiratorio bovino (VSRB) o por inmunosupresión debida al virus de la diarrea viral bovina (VDVB). La diseminación de estos microorganismos ocurre por contacto directo o por ingestión de alimento o agua contaminada por descargas nasales u orales de animales infectados. Es por eso que estas bacterias se diseminan rápidamente entre terneros que se encuentran confinados (feedlot), existiendo reportes previos donde se indica que a medida que el rodeo es más numeroso, aumenta el porcentaje de muertes por ERB ${ }^{14,25,54}$.

Los signos clínicos son variables, empezando con una leve pérdida del apetito hasta llegar al rechazo absoluto del alimento, depresión, cabeza y orejas caídas, incremento de la descarga nasal con cambios en la consistencia (desde transparente hasta viscosa y amarilla), aumento de la temperatura corporal, respiración forzada y tos, entre otros ${ }^{11,50,52}$. En Tabla 1 se detalla una escala de puntuación según signos depresivos y respiratorios en bovinos, tenida en cuenta para identificar animales con ERB.

\section{Farmacoepidemiología y resistencia a los antimicrobianos}

El agente patógeno aislado con mayor frecuencia en exudados nasofaríngeos y tejido pulmonar de animales muertos en feedlots es $M$. haemolityca (91\%), siendo común su asociación con VDVB. Otros microrganismos como $M$. bovis, $H$. somni, VSRB, PI-3 у $P$. multocida han sido aislados con menor frecuencia en este tipo de sistema productivo ${ }^{11,30}$, constatándose alta correlación entre los asilamientos de exudados nasofaríngeos y las muestras de tejido pulmonar. Estudios llevados a cabo en terneros de rodeos lecheros han demostrado que los agentes mayormente aislados fueron Pasteurella multocida y Micoplasma spp ${ }^{11,17,23}$. En Ar- gentina se reportó la presencia de cepas de $H$. somni, $M$. haemolytica y $P$. multocida en muestras de pulmón de animales con ERB ${ }^{15}$.

Para obtener datos epidemiológicos que ayudaran al entendimiento de la dinámica de las poblaciones de M. haemolytica dentro del feedlot, así como estimar el estado actual de su resistencia antimicrobiana a las drogas utilizadas, se realizó un estudio que reportó diferencias significativas en los aislamientos de $M$. haemolytica entre los animales muestreados al ingreso versus a la salida del feedlot sugiriendo que, si bien $M$. haemolytica es una bacteria comensal del tejido tonsilar del ganado, los terneros adquieren la infección bacteriana una vez en el sistema, ya sea por vía animalanimal o desde el medio ambiente ${ }^{29}$. Anteriormente se había demostrado la persistencia de $M$. haemolytica en lavajes traqueobronquiales durante 244 días en animales tratados con ATB ${ }^{46}$. También se logró identificar a M. haemolytica en muestras de alimento y agua sugiriendo que la transmisión desde el medio ambiente es posible ${ }^{7}$.

Dada la importancia de las bacterias en la patogenia de la ERB, los agentes antimicrobianos constituyen la herramienta terapéutica más utilizada para reducir la mortalidad asociada con esta enfermedad. La mayoría de estos ATB son aprobados para su uso por organismos reguladores sobre la base de la seguridad en los animales y en seres humanos que consumen productos cárnicos o lácteos. Su utilización en ERB puede ser terapéutica o preventiva. El uso terapéutico consiste en administrarlos a animales con signos clínicos en forma individual, mientras que el uso preventivo -conocido comúnmente como metafilaxis- implica el tratamiento de grupos de animales con alto riesgo de desarrollar ERB y riesgo potencial de colaborar en el desarrollo de bacterias resistentes ${ }^{40}$.

Los ATB utilizados en el tratamiento de las enfermedades del ganado bovino deberían ser seleccionados por el conocimiento del microorganismo involucrado 
en la enfermedad, ya sea por un patrón de sensibilidad in vitro del microorganismo como por el conocimiento de la farmacocinética del antimicrobiano elegido. Sumado a esto, en la elección de la terapia debería ser tenido en cuenta el costo de los antimicrobianos, el valor de los animales involucrados, las mejores tasas de curación, el tiempo de retiro diferente en la producción de leche y carne, así ccomo la pérdida de posibles ventas a futuro ${ }^{4}$.

Los tratamientos para ERB en animales identificados por signos clínicos como depresión, anorexia y aumento de la temperatura $\left(>40^{\circ} \mathrm{C}\right)$ se basan en la utilización de macrólidos u otros ATB como $\beta$-lactámicos, fluorquinolonas, sulfonamidas o tetraciclinas ${ }^{13}$. Las tetraciclinas de acción prolongada (oxitetraciclinas), así como la tilmicosina, gamitromicina (macrólido) y florfenicol son ATB efectivos que mantienen niveles terapéuticos sanguíneos durante períodos no menores de 3 días y niveles inhibitorios en tejido pulmonar por aún más tiempo. Dadas sus ventajas, dichos ATB de acción prolongada suplantaron a los productos convencionales que debían aplicarse durante 3 días consecutivos.

Reportes previos aseveran que los antimicrobianos administrados a la llegada de los animales a los corrales de engorde han demostrado efectos positivos en la salud animal, el rendimiento y la economía del sistema $^{2,5}$. Para evaluar la eficacia de la gamitromicina (azálido perteneciente a los macrólidos sintéticos), se constató que al administrar dicho fármaco de manera preventiva para el control de ERB en el campo, tal aplicación produjo protección prolongada contra la exposición posterior de bacterias virulentas ${ }^{3,16}$.

La resistencia a los antimicrobianos es un problema que se va incrementando al involucrar cada vez más especies bacterianas causantes de infección tanto en animales como en seres humanos, resultando una de las mayores problemáticas sanitarias de la actualidad ${ }^{9}$, $12,22,29,31,33,55$. El aumento de bacterias resistentes a los ATB representa una importante amenaza sanitaria, que sumada a la ausencia de nuevos fármacos antimicrobianos en desarrollo, se han convertido en los principales problemas en la salud pública y animal ${ }^{8}$. Hoy en día la elección de una terapia antimicrobiana inapropiada conlleva riesgos significativos tanto para el animal como para el propietario, generando un fuerte impacto negativo en la economía de las empresas.

Los estudios llevados a cabo para evaluar la prevalencia de los patógenos bacterianos y caracterizar su susceptibilidad a los ATB, resultan de especial interés para poder comprender la importancia de la resistencia a dichos fármacos. En una investigación se determinó que el $72 \%$ de los aislamientos de M. haemolytica y el $50 \%$ de los aislamientos de $P$. multocida fueron resistentes a ATB, habiendo presentado el $30 \%$ de $M$. haemolityca y el 12,5 de P. multocida resistencia a más de siete clases de antimicrobianos entre los que se incluyen aminoglucósidos, penicilina, fluorquinolonas, lincosamidas, macrólidos, pleuromutilinas y tetraciclinas ${ }^{30}$. Sin embargo, la aparición de resistencia a los antimicrobianos varía según los países y regiones, lo cual complica la adopción de estrategias y demanda la realización de análisis y estudios en cada región en particular.

Si bien las neumonías bacterianas pueden tratarse con diversos ATB, varios estudios reportan el aumento de la falta de respuesta a los tratamientos. La presencia de animales positivos a gérmenes de la familia Pasteurellaceae ha sido verificada con mayor frecuencia en sistemas intensivos de engorde, antes que en terneros de leche o de cría. La prevalencia de los aislamientos resistentes a por lo menos un antimicrobiano fue de $17,6 \%$ en rodeos de leche, $21,9 \%$ en rodeos de cria y $71,9 \%$ es sistemas intensivos de engorde ${ }^{9}$.

Una investigación norteamericana determinó que en el ganado bajo estudio fueron más comunes las bronconeumonías crónicas que las agudas y que estos pacientes habían recibido múltiples tratamientos, sugiriendo una falta de respuesta a la terapia antimicrobiana ${ }^{31}$. Resulta llamativo que el ganado con bronconeumonía aguda haya sido tratado varias veces, sugiriendo que la infección en un inicio no haya sido bacteriana. En este estudio la mayoría de los aislamientos fueron mixtos, siendo los de mayor frecuencia los de M. haemolytica y $M$. bovis al igual que lo reportado en otro trabajo ${ }^{55}$. En un ensayo realizado en Oklahoma, los aislamientos de $M$. haemolytica suceptibles a tilmicosina y florfenicol disminuyeron significativamente entre 1994 a 2002, mientras que los porcentajes de suceptibilidad a ceftiofur, enrofloxacina y trimetroprima-sulfametoxazol se mantuvieron estables ${ }^{55}$.

Los porcentajes de aislamientos de P. multocida suceptibles a tilmicosina, florfenicol, trimetoprimasulfametoxazol y tetraciclina también han declinado significativamente, mientras que los porcentajes de susceptibilidad a ceftiofur y enrofloxacina permanecieron estables. H. somni fue susceptible a todos los antimicrobianos analizados durante el periodo en estudio ${ }^{55}$. Estos trabajos sugieren que a pesar de que muchos de los antimicrobianos analizados pueden ser efectivos para el tratamiento de la ERB, aún no se ha logrado disminuir el porcentaje de mortalidad.

En los últimos veinte años la industria veterinaria ha seleccionado y desarrollado nuevas formulaciones farmacéuticas de ATB de una sola dosis, capaces de distribuirse masivamente en el tracto pulmonar de los bovinos, facilitando el manejo en los establecimientos ganaderos. De esta manera, primariamente surgió la formulación de danofloxacina 18\% (fluorquinolona de segunda generación, bactericida y con características "concentración dependiente"), la cual sextuplicó la dosis a $6.25 \mathrm{mg} / \mathrm{kg}$ con el propósito de aprovechar su alto pico de concentración en pulmón para eliminar los patógenos pulmonares del tracto respiratorio ${ }^{35}$.

Posteriormente, se desarrollaron nuevas moléculas del tipo de los macrólidos complejos como tilmicosina, azalidas (gamitromicina) y triamilidas (tulatromicina). Todas estas moléculas poseen características bacteriostáticas y de alta liposolubilidad lo que hace que sus 
bajas concentraciones plasmáticas no se correlacionen con sus altas concentraciones en el tejido pulmonar y otros tejidos blandos. Actualmente en Argentina, tilmicosina es la molécula masivamente usada en los tratamientos de ERB en feedlots. Esto puede traer aparejado el desarrollo de genes determinantes de resistencia por diferentes géneros bacterianos. Gamitromicina es una nueva molécula que ha sido aprobada para uso en enfermedades respiratorias bovinas en nuestro país y ha demostrado tener más potencia sobre cepas resistentes a otros macrólidos $2,3,5,16$.

Sin embargo, surge el problema de la resistencia a los macrólidos, la cual se contextualiza dentro de lo que se denomina "resistencia lateral", que implica que al encontrar genes resistentes a una sola molécula perteneciente al grupo antes mencionado, invalidaría el uso de toda esta familia de novedosos fármacos desarrollados específicamente para el tratamiento de ERB ${ }^{12}$.

En la Provincia de Buenos Aires (Argentina), se ha observado un alto y significativo grado de morbilidad por neumonía en los animales sometidos a cría de feedlot, con porcentajes elevados de mortandad tras la aplicación de reiterados tratamientos sin obtención de una respuesta adecuada. Al no existir un programa consensuado de tratamientos farmacológicos para ERB, los animales son tratados casi en su totalidad en forma empírica con el macrólido tilmicosina, siendo los resultados de eficacia clínica muy variables, con alto riesgo de generar cepas resistentes. Por este motivo y asumiendo que las cepas bacterianas persisten en el medio ambiente del establecimiento, se sugiere una rotación de grupos químicos al momento de tratar esta patología.

Estudios recientes han tenido por objeto evaluar los mecanismos de resistencia de las bacterias involucradas en la ERB. Aunque los mecanismos de resistencia bacteriana a los macrólidos y lincosamidas están ampliamente estudiados, los conocimientos de tales mecanismos siguen siendo investigados en la familia Pateurellaceae. Así, en aislamientos de P. multocida y $M$. haemolytica se han logrado identificar tres nuevos genes de resistencia: rRNA gen metilasa erm (42), gen transportador de macrólidos $m s r(\mathrm{E})$ y gen fosfotransferasa de macrólido $m p h$ (E). El determinante de resistencia, denominado erm (42), se encontró completamente conservado en seis aislamientos de M. haemolytica y $P$. multocida, lo cual sugiere transferencia de genes entre estas especies ${ }^{12,13,27}$.

\section{CONCLUSIÓN}

Debido a la escasa información sobre las cepas actuantes en la enfermedad respiratoria bovina en Argentina, resulta de vital importancia encarar la determinación de patrones de resistencia a las cepas bacterianas involucradas con dicha afección a niveles regionales. Es factible que la aplicación de tal conocimiento provoque un favorable impacto sobre la salud humana y animal, al concientizar un uso más racional de los antibióticos, así como alertar acerca de la relación directa entre el empleo indiscriminado de tales fármacos con la aparición y permanencia de cepas bacterianas resistentes.

\section{REFERENCIAS}

1. Allan EM, Wiseman A, Gibbs HA, Selman IE. 1985. Pasteurella species isolated from the bovine respiratory tract and their antimicrobial sensitivity patterns. Vet Rec 117: 629-631.

2. Amrine DE, White BJ, Larson RL, Mosier DA. 2014. Pulmonary lesions and clinical disease response to Mannheimia haemolytica challenge 10 days following administration of tildipirosin or tulathromycin. J Anim Sci 92: 311-319.

3. Baggott D, Casartelli A, Fraisse F, Manavella C, Marteau R, Rehbein S, Wiedemann M, Yoon S. 2011. Demonstration of the metaphylactic use of gamithromycin against bacterial pathogens associated with bovine respiratory disease in a multicentre farm trial. Vet Rec 168: 241249.

4. Bateman KG. 2003. Antimicrobial drug use in cattle. In: Antimicrobial Therapy (Prescott JF, Baggot JD, Walker RD, ed), 3rd edn, Iowa State Press, Ames (USA), p. 574-611.

5. Booker CW, Abutarbush SM, Schunicht OC, Jim GK, Perrett T, Wildman BK, Guichon PT, Pittman TJ, Jones C, Pollock CM. 2007. Evaluation of the efficacy of tulathromycin as a metaphylactic antimicrobial in feedlot calves. Vet Ther 8: 183-200.

6. Boyce JD, Harper M, Wilkie IW, Adler B. 2004. Pasteurella. In: Pathogenesis of bacterial infections in animals (Gyles CL ed), 3rd ed., p. 325-341.

7. Burriel AR. 1997. Isolation of Pasteurella haemolytica from grass, drinking water, and straw bedding used by sheep. Curr Microbiol 35: 316-318.

8. Carlet J. 2014. The WAAAR declaration against antibiotic resistance. World Alliance Against Antibiotic Resistance. http://www.waaar.org

9. Catry B, Haesebrouck F, Vliegher S, Feyen B, Vanrobaeys M, Opsomer G, Schwarsz S, Kruif A. 2005. Variability in acquired resistance of Pasteurella and Mannheimia isolates from the nasopharynx of calves. $M i$ crob Drug Resist 11: 387-394.

10. Costa EF, Giuliodori MJ, Dezzilio M, Romero J. 2003. Mortalidad en un feedlot de La Plata (Buenos Aires-Argentina): causas, distribución mensual e impacto económico. Analecta Vet 23: 13-19.

11. Dabo SM, Taylor JD, Confer AW. 2007. Pasteurella multocida and bovine respiratory disease. Anim Health Res Rev 8: 129-150.

12. Desmolaize B, Rose S, Warrass R, Douthwaite S. 2011. A novel Erm monomethyltransferase in antibiotic-resistant isolates of Mannheimia haemolytica and Pasteurella multocida. Mol Microbiol 80: 184-194.

13. Desmolaize B, Rose S, Wilhelm C, Warrass R, Douthwaite S. 2011. Combinations of macrolide resistance determinants in field isolates of Mannheimia haemolytica and Pasteurella multocida. Antimicrob Agents Chemother 55: 4128-4133. 
14. Edwards AJ. 1996. Respiratory diseases of feedlot cattle in the central USA. Bovine Pract 30: 5-7.

15. Fiorentino MA, Moreira AR, Malena R, Mendez A, Paolichi F. 2012. Sensibilidad a antimicrobianos en cepas de Histophilus somni, Mannheimia haemolytica y Pasteurella multocida aisladas de pulmones bovinos. XIX Reunión Cientif. Técn. Asoc. Arg. Vet. Lab. Diagn. (AAVLD), Buenos Aires.

16. Forbes AB, Ramage C, Sales J, Baggott D, Donachie5 W. 2011. Determination of the duration of antibacterial efficacy following administration of gamithromycin using a bovine Mannheimia haemolytica challenge model. Antimicrob Agents \& Chemother 55: 831-835.

17. Francoz D, Buczinski S, Bélanger AM, Forté G, Labrecque O, Tremblay D, Wellemans V, Dubuc J. 2015. Respiratory pathogens in Quebec dairy calves and their relationship with clinical status, lung consolidation, and average daily gain. $J$ Vet Intern Med 29: 381-387.

18. Fulton RW, Cook BJ, Step DL, Confer AW, Saliki JT, Payton ME, Burge LJ, Welsh RD, Blood KS. 2002. Evaluation of health status of calves and the impact on feedlot performance: assessment of a retained ownership program for postweaning calves. Canad J Vet Res 66: 173-180.

19. Fulton RW, Blood KS, Panciera RJ, Payton ME, Ridpath JF, Confer AW, Saliki JT, Burge LT, Welsh RD, Johnson BJ, Reck A. 2009. Lung pathology and infectious agents in fatal feedlot pneumonias and relationship with mortality, disease onset, and treatments. J Vet Diagn Invest 21: 464-477.

20. Gioia J, Qin X, Jiang $\mathbf{H}$ et al. 2006. The genome sequence of Mannheimia haemolytica A1: insights into virulence, natural competence, and Pasteurellaceae phylogeny. $J$ Bacteriol 188: 7257-7266.

21. Griffin D, Chengappa MM, Kuszak J, McVey DS. 2010. Bacterial pathogens of the bovine respiratory disease complex. Vet Clin North Am 26: 381-394.

22. Hendriksen RS, Mevius DJ, Schroeter A et al. 2008. Prevalence of antimicrobial resistance among bacterial pathogens isolated from cattle in different european countries: 2002-2004. Acta Vet Scand 50: 28.

23. Hotchkiss EJ, Dagleish MP, Willoughby K, McKendrick IJ, Finlayson J, Zadoks RN, Newsome E, Brulisauer F, Gunn GJ, Hodgson JC. 2010. Prevalence of Pasteurella multocida and other respiratory pathogens in the nasal tract of scottish calves. The Vet Rec 167: 555-560.

24. Inzana TJ, Corbeil L. 2004. Haemophilus. In: Pathogenesis of Bacterial Infections in Animals (Gyles L ed), 4th ed., Willey, Chichester (UK), p. 243-250.

25. Irsik M. 2010. Bovine respiratory disease associated with Mannheimia haemolytica or Pasteurella multocida. On line: athttp://edis.ifas.ufl.edu

26. Jaramillo-Arango CJ, Trigo FJ, Suárez F. 2009. Bovine mannheimiosis: etiology, prevention and control. Vet Méx 40: 293-314.

27. Kadlec K, Brenner MG, Sweeney MT, Brzuszkiewicz E, Liesegang H, Daniel R, Watts JL, Schwarz S. 2011. Molecular basis of macrolide, triamilide, and lincosamide resistance in Pasteurella multocida from bovine respiratory disease. Antimicrob Agents Chemother 55: 2475-2477.
28. Katsuda K, Kohmoto M, Mikami O. 2013. Relationship between serotype and the antimicrobial susceptibility of Mannheimia haemolytica isolates collected between 1991 and 2010. Res Vet Sci 94: 205-208.

29. Klima CL, Alexander TW, Read RR, Gow SP, Booker CW, Hannon S, Sheedy C, McAllister TA, Selinger LB. 2011. Genetic characterization and antimicrobial susceptibility of Mannheimia haemolytica isolated from the nasopharynx of feedlot cattle. Vet Microbiol 149: 390-398.

30. Klima CL, Zaheer R, Cook SR, Booker CW, Hendrick S, Alexander TW, McAllister TA. 2014. Pathogens of bovine respiratory disease in North American feedlots conferring multidrug resistance via integrative conjugative elements. J Clin Microbiol 52: 438-448.

31. Lamm CG, Love BC, Krehbiel CR, Johnson NJ, Step DL. 2012. Comparison of antemortem antimicrobial treatment regimens to antimicrobial susceptibility patterns of postmortem lung isolates from feedlot cattle with bronchopneumonia. J Vet Diag Inv 24: 277-282.

32. Lopez A. 2012. Respiratory system, mediastinum and pleurae. In: Pathologic Basis of Veterinary Disease (Zachary JF, McGavin MD, Ed), $5^{\circ}$ ed., Elsevier, Philadelphia, p. 458-538.

33. Lubbers BV, Hanzlicek GA. 2013. Antimicrobial multidrug resistance and coresistance patterns of Mannheimia haemolytica isolated from bovine respiratory disease cases a three-year (2009-2011) retrospective analysis. $J$ Vet Diag Inv 25: 413-417.

34. Margineda C, Bessone F, Adrien J, Pianetti V, Morao G, Piscitelli H, Zielinski G. 2014. Sensibilidad antimicrobiana de Pasteurella multocida aisladas de pulmones bovinos de un establecimiento de engorde a corral. II Jorn Lat Fac Cs Vet, UNR (Rosario, Argentina).

35. McKellar Q, Sánchez SF, Jones D. 2004. Pharmacokinetic/pharmacodynamic relationship of antimicrobial drugs used in veterinary medicine. $J$ Vet Pharm Therap 27: 506-514.

36. Miranda A, Zielinski G, Rossanigo G. 2013. Sanidad en feedlot. Boletín Técnico $N^{\circ}$ 96, Instituto Nacional de Tecnología Agropecuaria (INTA). On line: http://inta.gob.ar/ documentos/sanidad-en-feedlot/

37. Moore SJ, O'Dea MA, Perkins N, O'Hara AJ. 2015. Estimation of nasal shedding and seroprevalence of organisms know to be associates with bovine respiratory disease in Australian live export cattle. $J$ Vet Diagn Invest 27 : 6-17.

38. Morck DW, Merrill JK, Thorlakson BE, Olson ME, Tonkinson LV, Costerton JW. 1993. Prophylactic efficacy of tilmicosin for bovine respiratory tract disease. $J$ Am Vet Med Assoc 15: 273-277.

39. Mosier DA. 1997. Bacterial pneumonia, bovine respiratory disease update. Vet Clin North Am 13: 483-493.

40. Nickell JS, White BJ. 2010. Metaphylactic antimicrobial therapy for bovine respiratory disease in stocker and feedlot cattle. Vet Clin North Am Food Anim Pract 26: 285-301.

41. Panciera RJ, Confer AW. 2010. Pathogenesis and pathology of bovine pneumonia. Vet Clin North Am Food Anim Pract 26: 191-214. 
42. Ponti D, Piperata M. 2014. Indicadores ganaderos, Anuario 2014. Public. Ministerio de Agricultura, Ganaderia y Pesca. http://www.minagri.gob.ar/site/ganaderia/bovinos/02-Informacion\%20sectorial/01=Indicadores/_Anuario/000001indicadores \%20bo vinos\%202012-2014.pdf

43. Rademacher RD, Buczinski S, Tripp HM, Edmonds MD, Johnson EG. 2014. Systematic thoracic ultrasonography in acute bovine respiratory disease of feedlot steers: impact of lung consolidation on diagnosis and prognosis in a case control study. Bov Pract 48: 1-10.

44. Rice JA, Carrasco L, Hodgins DC, Shewen, PE. 2007. Mannheimia haemolytica and bovine respiratory disease. Anim Health Res Rev 8: 117-128.

45. Rossanigo CE, Bengoelea A, Sager RL. 2008. Enfermedades bovinas en sistemas intensivos de la región semiárida-subhúmeda central. Rev Arg Prod Anim 28: 303-334.

46. Rowe HA, Poxon IR, Donachie W. 2001. Survival of Mannheimia (Pasteurella) haemolytica in tracheobronchial washings of sheep and cattle. Vet Microbiol 81: 305-314.

47. Siddaramppa S, Inzana TJ. 2004. Haemophilus sommus virulence factors and resistance to host immunity. Anim Health Res Rev 5: 79-93.

48. Smith RA. 1998. Impact of disease on feedlot performance: A Review. J Anim Sci 76: 272-274.

49. Smith RA. 2004. Feedlot diseases and their control. Proceedings of the 23rd World Buiatrics Congress, Québec City, Canada. http://www.ivis.org/proceedings/wbc200 4-smith-simple.pdf
50. Singh K, Ritchey JW, Confer AW. 2011. Mannheimia haemolytica: bacterial-host interactions in bovine pneumonia. Vet Pathol 48: 338-348.

51. Taylor JD, Fulton RW, Lehenbauer TW, Step DL, Confer AW. 2010. The epidemiology of bovine respiratory disease: What is the evidence for preventive measures? Can Vet J 51: 1351-1359.

52. Trigo F. 1987. El complejo respiratorio infeccioso de los bovinos y ovinos. Ciencia Vet 4: 1-36.

53. Villard L, Gauthier D, Maurin F, Borges E, Richard Y, Abadie G, Kodjo A. 2008. Serotypes A1 and A2 of Mannheimia haemolytica are susceptible to genotypic, capsular and phenotypic variations in contrast to T3 and T4 serotypes of Bibersteinia (Pasteurella) trehalosi. FEMS Microbiol Lett 80: 42-49.

54. Vogel GL, Parrott JC. 1994. Mortality survey in feedyards. The incidence of death from digestive, respiratory and other causes in feedyards in the Great Plains. Comp Cont Ed Pract Vet 16: 227-234.

55. Welsh RD, Dye LB, Payton ME, Confer AW. 2004. Isolation and antimicrobial susceptibilities of bacterial pathogens from bovine pneumonia: 1994-2002. J Vet Diagn Invest 16: 426-431.

56. Zecchinon L, Fett T, Desmecht D. 2005. How Mannheimia haemolytica defeats host defense through a kiss of death mechanism. Vet Res 36: 133-156. 